\title{
MAKING INTELLECTUAL ROOM FOR PERSONA STUDIES: A NEW CONSCIOUSNESS AND A SHIFTED PERSPECTIVE
}

\author{
P. DAVID MARShall AND Kim BARBOUR
}

It is an enormously difficult—and perhaps impossible, but ultimately important—task to comprehensively define the contemporary moment through a particular concept. This introduction and this journal make the claim that both in a pervasive way and to a pandemic extent, there is enormous activity and energy in the production, construction, and exhibition of personas. Something quite extraordinary has shifted over the last twenty years that has led to this intensive focus on constructing strategic masks of identity. The catalyst is the development of online culture and its invocation to personalize the expression of a public self-essentially a persona-regularly and incessantly. This culture of producing and monitoring our public selves is the focus of this journal as online culture blends with everyday culture and leads to an insistent proliferation of personas for both presentation and for strategic purposes in order to manage very new notions of value and reputation. The task of investigating persona is complex, and is dependent on connections and intersections across an array of disciplines. This journal and the field of Persona Studies is designed to serve as a site for this essential work of comprehending, analysing, and critiquing persona, and to allow disciplines to intersect, exchange ideas, and debate the play of persona historically and in contemporary culture.

What follows in this introduction is both a defence and proclamation of the need to both investigate persona and do so in a formal, official venue like a journal. Persona Studies identifies a lacuna of essential and emerging work that has been overlooked by many journals. In addressing these questions, this journal's introductory essay provides a map of the concept of persona. From this vantage point, we identify where what we call Persona Studies fits into the academy and intellectual currents-in other words, what are its intellectual relations, antecedents, and sources that will help us both discern its likely directions as it ventures forward, as well as its points of differentiation. Some of the answers are beyond the scope of a single essay, and hence the journal's mission is activated in this first issue. The collection of articles in our inaugural issue identify some of these future directions for Persona Studies, and the authors use many of the sources we introduce below, sources we see as foundational to an emerging way of thinking. This essay is designed to justify making room in the academy for Persona Studies, and to assist those in parallel academic traditions to see the advantages of the particular range of lenses that Persona Studies privileges in its analyses.

\section{THE UsES OF PERSONA: AN HISTORICAL AND ETYMOLOGICAL ROADMAP}

Intellectual inquiry is often driven by how a concept identifies a particular understanding of an object, a process, or a condition. Persona's peculiar value as a term is the way that it helps describe and articulate the relationship between the individual and the social. 
More specifically, persona helps us understand the construction, constitution, and production of the self through identity play and performance by the individual in social settings.

The word persona is derived from the Latin, and its original meaning is very close to the idea of "mask." As the Oxford Dictionary traces its etymology to its Etruscan origins, it relates persona to the word Prosopon - the ancient Greek term for the mask traditionally worn in dramas as well as religious rites. The Greek theatrical mask has served as the indexical sign of drama for thousands of years, and the word prosopon is the Greek etymological root word for persona ${ }^{1}$.

Embedded in the meaning of the word persona from these connections to the prosopon and Greek performance is the utility of the mask to simplify and convey the identity of a character to an audience at some distance. Indeed, the word persona is etymologically connected to the idea of sound-sona-moving or projecting through wood-per-of the mask itself. The mask as persona also allowed early Greek allow actors to play more than one role, while the uniformity of some masks, such as those used by the Chorus, created a univocal identity.

From these classical origins in Greece, one can see how persona begins to embody a particular way in which individuals move into social settings. Theatrical performance becomes a formalistic expression of presentation, but also one designed for display to others. From this original usage of the word, personas ${ }^{2}$ are ways of being that are not necessarily modelled on truth, but are forms of presentation and performance for certain effects. Personas, in the most general sense then, are a strategic form of communication.

The use of "persona" was far from static in antiquity. However, it nonetheless articulated with some consistency an intellectual trajectory around personhood that is distinct from the search for the true self that has enveloped psychological study. Reiss, for instance, details the way that Cicero, the Roman philosopher and politician, interpreted persona in its plurality in the individual and claimed that a different constitution of individuality was part of Roman experience more broadly (Reiss 127 - 138). Cicero identified four personas making up the individual. The first two were what he described as "common" and "singular" (127). The "common" persona identified the virtues that differentiate us from the rest of the animal kingdom and "fundamental states of the soul," and allowed the person to move through and conduct themselves for the organization of "societas," what Cicero called a decorum and moral rightness (honestum) (127). The singular persona or role referred to specific abilities and "inclinations" that an individual brought to their being. For Cicero, this singular persona was also under the disciplines of decorum and the associated rules and virtues of the social. The third persona was determined by received or acquired status - thus one's social, economic, and political position was also constrained by decorum and the social dimensions of these positions (128). Reis identifies Cicero's fourth and final persona also operated within this social environment organised by decorum, but Cicero described it as our identity of voluntary choice. All personas that Cicero identified were part of the human being and fit into the structure of community and the virtues of what this entailed.

Reiss' interpretation of Cicero's personas underlines that individuality as we understand it today has been framed and conceived differently in other historical periods and these other formulations should not be taken as congruent with our contemporary notions. Nonetheless, these conceptions of persona identify the understanding of the self from its position in the social and the natural world (to use Cicero's terms) of the community. Persona once again describes the peculiar relation of the individual to the social in its production and enactment by individuals. This quality that situates persona as a point of individual negotiation with the social 
is ultimately what is valuable and also what has some continuity to our own equally peculiar construction and constitution of identity in this contemporary moment.

What can be discerned from this tour of persona as a concept in antiquity is that it helps to delineate the relationships that we negotiate as individuals between the private, the public, and the intimate. These ideas, along with more recent conceptualisations of persona, offer a starting point and a language for the study of identity at a time of increasing complexity in identity performance. As Hannah Arendt's remarkable reading of classical ancient Greek culture explains, the divide between the public and private was much more well-developed and articulated through a distinctive and strategic public identity. Classical ancient Greek culture made it clear that there were clearly delineated spheres of the domestic or home, and public life. The character or identity of an individual was not continuous between these realms. One constituted a public identity for its play in the disputes and debates of the political realm - the polis - and another for use in the realm of the affairs of the household-the oikos (Arendt 185). For Arendt, this separation of the private and the public was essential for the development of the political persona of citizen. From Arendt's position, in fact, one of the key failures of contemporary politics was the blending of these two personas-the private person and the public person in the public realm. In contra distinction to the developing feminist proclamation that "the personal is political," Arendt saw the need to construct clear and separate public and private identities. What can be discerned from this understanding of the public and the private is a nuanced sense of the significance of persona: the presentation of the self for public comportment and expression (Allard, 25-43).

Despite this historical richness in the meaning of persona, it has to be acknowledged that it was not a concept that was used with any frequency before the twentieth century. Its use appeared from two related directions. In the new literary traditions emerging at the beginning of the twentieth century, persona became a term that certain poets such as Ezra Pound connected to a movement called imagism and used to describe the subsumption of their identity into the object or subject they were describing. Whether it was a tree, a setting, or a person, the language of expression produced a persona or character that was beyond the authorial identity. In contrast to the affective romantic expression of the self, Pound's use of persona was designed to separate the poet's identity from the poem itself-a kind of characterisation-that described his work in the Cantos. Pound, along with TS Eliot and others, helped define this different relationship to the self in modern literature, a path quite divergent from the consciousness of self as a form of expression represented by contemporaries such as James Joyce and Faulkner. Baddick summarizes this use of persona in literary criticism: "the assumed identity or fictional 'I' ... assumed by a writer in a literary work; thus the speaker in a literary poem, or the narrator in a fictional narrative" (qtd. in Fowler and Burchfield 588).

The other site for the development and deployment of the term persona was in psychology. Whereas Freud's notion of the unconscious clearly informed the development of modernist fiction's self-consciousness in much of twentieth-century literature (as identified above via Joyce and Faulkner), Carl Jung's different configurations of archetypes and anima provided at least an alternative source for understanding the relationship between the self and the social. Jung used the word persona sparingly but significantly in his work, which has actually made it relatively straightforward to identify how he defined it. For Jung, persona is "the arbitrary segment of the collective psyche" that the individual inhabits as "a mask that feigns individuality, making others and oneself believe that one is individual, whereas one is simply acting a role through which the collective psyche speaks" (Two Essays 157). Jung's approach to the unconscious is fundamentally different to that of Freud in its appeal to a kind of universal human unconsciousness-a collective unconscious as opposed to a collective psyche-that 
must be reached, and thereby dismantles the arbitrary and not fully formed presentation of the "outer personality" or persona, and not the "inner-personality" or anima (Psychological Types 466-67). Persona is influenced by "adaptation to the [social] environment" (Psychological Types 469-470) and a concerted effort to make oneself understood and recognized in that social environment. As Jung explains it, persona is designed "to impress and conceal" (qtd. in Fawkes 4).

Jung's idea of persona captures some key elements of why persona is useful to both analyse and read the contemporary condition. The mask of the individual-the persona-is derived from the social environment: it is constituted from that interaction between the social and the individual, and stands for the individual in the social. From reading Jung, persona represents something that needs to be overcome, or at least recognised for its threatening potential for leading to an unbalanced self where this externally driven identity can be mistaken for the whole being and there is "minimal" integration made with "one's own" inner self or "individuality" (Two Essays 302). What is essential to understand from Jung's approach is that persona is a strategic public identity, not necessarily in tension with an inner soul of self and individual (which Jung also acknowledges can overwhelm the connection and balance with the social identity (Two Essays 303)), but a way to manage the various dimensions of life and its public formation of the self. Persona can be seen as something that needs to be managed and, from this perspective, to be understood as a personal practice that is performed in order to enter the social world in some particular way.

Conceptually, the emerging twentieth-century reading of persona from either Jung or literature is, generally, a narrative of falseness and fiction. Persona is a separation from truth. Fiction merges the idea of persona with character or personnage to use the French form of the word. There is no question that this study of character has informed some of the most interesting directions in performance studies over the last century where the study of the fictional character has been explored through both theatre and film (see Landy Performance and Persona). By extension, these ideas of persona have moved comfortably into a description of the false nature of presentation in politics as well. In a similar vein, theological studies and literary approaches to character have developed forms of exegesis of biblical texts and novels, to develop interpretive readings of these texts: not definitive notions of truthfulness or falsity, but rather positional and contingent. These kinds of hermeneutics, which acknowledge the idea of the relative and strategic posture of different versions of the self, have offered useful comparative readings through character analysis of persona, and how individuals are involved in similar constructions of public identity.

Extending this idea of persona as performance is Erving Goffman's influential text Presentation of Self in Everyday Life. Taking the dramaturgical analogy to its full extent, Goffman described the performance of self as a series of roles similar to characters, which we inhabit in different spaces and for different purposes. Those roles come with front and back stages, and settings that have recognisable elements: a lab coat, a large desk, a book-lined office, a particular hat. It is the interaction of these elements with the performance of the individual that allows the role to become legible, the persona identifiable. Goffman's conceptualisation of the performance of self gives Persona Studies scholars a way to directly analyse the way a persona is enacted by an individual. Also useful is the fact that the terminology utilised by Goffman is familiar and translates easily from physical to digital spaces-a core necessity as the performance of self becomes increasingly visible through online platforms such as social and professional networking sites. 
Goffman's work has also inspired the new emerging theory of performance registers. By considering complexity of role performance in contemporary digital society, we see the overlapping of persona performances by a single individual requires new explanatory terminology. In conceptualising registers of performance, we address the strategies used by us all in performing different elements of a persona to different audiences, often in the same performance space. We use the metaphor of vocal registers as a starting point, which differentiates between types of vocal sounds that can be created by a single voice (Hollien 1). In her study of the online persona creation practices of artists, Kim Barbour theorised professional, personal, and intimate registers of performance, and we see this as usefully dealing with the potential problems associated with the context collapse inherent in the use of online networking sites to connect with family, friends, colleagues, and strangers. The registers are ways of looking at particular types of performances, those roles we play for the purpose of connecting, differentiating, and engaging with our personal and professional communities. By foregrounding the agency of the individual performer, registers also allow us to study the individual as empowered in the process of creating and enacting of their personas.

Throughout the twentieth century, persona moved gradually into much more common usage. More or less, it has maintained its connection to the fictive in various capacities and, in name only, is often linked to Goffman's work; but because of its association with Jungianinspired psychoanalysis, it has also been associated with a psychological inflection in its deployment of character and personnage. One of Ingmar Bergman's most famous films, Persona (1964), emphasizes the link between the relationship of performance and psychology. The film itself is seen as a classic text that disorients the viewer from a fixed position within the story. Persona then is explored through the film not only through the characters themselves but also through clear allusions that draw the attention of the audience to the fabrication of the performance itself: the opening scene for instance shows the film sprocket and the spark that illuminates the projector. The "patient" identified in the film is presented as a famous actress, but has chosen a new presentation of the self where she does not speak. The nurse who cares for the actress talks incessantly as though experiencing herself some form of Freudian-inspired talking cure, a strategy that challenges our understanding, reading, and delineation of patient and carer roles. The film works to disturb the fixity of identity, but also interrogates the selfproduction of new identities as fabricated personas. Persona is organized and presented by Bergman and his actors as a way for the individual to negotiate his or her social role and position.

It is important to understand persona as very much connected to performance, as both Goffman's study of the everyday underlines, and as Bergman's reading of the public and private self engenders in his film. To fully understand the play of persona in contemporary culture, it is necessary to integrate the thinking of Judith Butler on performativity and gender. Butler claims in Gender Trouble that gender is a discursive construction and, like identity itself when thought of as persona, is not fixed or biologically grounded. Unlike performance, Butler's concept of performativity does not acknowledge the presence of a subject or enacting of a subject. Performativity of gender then is bringing into being a constitutive construction of gender. What Butler's approach to gender and performativity allows us to see is that the range of identities that we associate with gender are performative spaces that are strengthened through their reiteration through discourse and enactments by individuals. Persona then can be thought of as a similar construction, a resignification of identity that relies on what is playable and performable in the public world. Thus, a persona is a reinforced form of performativity that can produce a professional identity, a political identity, or an entertaining identity for various individuals to inhabit. Butler's work also allows us to begin further exploring our registers of performance of persona and the purposes we have behind these efforts and their relation to 
dominant and collectively constructed identities. Persona, by the very word (as Goffman's work also emphasises), implies that there is something behind the mask-another persona that reveals some connection to dimensions that are usually called private or intimate. These further dimensions of the constructed and performative structure of identity are the registers that we inhabit and sometimes now deploy more publicly in the era of online culture and social media. Anthony Giddens' work on understanding how the self and the social intersect in the formation of a malleable modern identity (32-34) is another useful way to understand how the contemporary moment produces new pushes towards both forms of revelation and forms of performativity that allow the social to move into the territories of the previously private and intimate.

If there is a single impetus behind this journal's genesis, it is related to how online culture specifically has demanded a reconsideration of the public projection of the self. The origins of this transformation of the public self can be seen in outline in the early days of the Internet and, in particular, the World Wide Web. In contrast to Sherry Turkle's first reading of online identity that focused on anonymity and play, by the mid-1990s when the Web was beginning to be prevalently explored and deployed, the projection of a visible public self was becoming increasingly standardized. The focus has shifted from the classic The New Yorker claim that online no one knows you are a dog, to the implementation of "real names" policies and the expectation that online identities are authentic representations of an offline self. Interestingly, David Foster Wallace, in his novel Infinite Jest, described with a certain perverse prescience the need to present a mask to the world in this new connected culture where telephones transformed into "videophonic calls." Wallace described how individuals became uncomfortable with the video image of themselves (a general psychological condition he labelled "Video-Physiognomic Dysphoria: VPD" ) and clever entrepreneurial companies began developing High Definition video masks to help individuals present better versions of themselves for others to see without imperfections (148). These masks also included "improved" features such as attentive facial expressions for the caller to feel comfortable that the person stayed focussed and empathetic (149). Even these were replaced in Wallace's imagined near-future parallel world by still photographs of good-looking models-what Wallace described as a new market for the pleasing-to-the-eye performers who ended up on infomercials-presenting full-body versions of any caller (150-151).

Although fictional, Wallace's humourous exposé of the development of public masks in widespread use does identify the way in which online culture demands a regular and insistent presentation of the self. Online gaming culture similarly has pushed its players into constructing public identities with even greater complexity In the online environment the gamer developed a simultaneous parallel and dual public identity. On one level, an avatar, in the tradition of Second Life or in role-playing games such as World of Warcraft, defined the online game identity of a player. However, because of the capacity to engage in online chat and develop teams and networks of related players, the avatar became a visible version of identity that was twinned with real-time discussions and engagements by the player him or herself. In effect, the avatar became a persona that was linked to another persona of the online gaming identity that the player inhabited when texting or talking with other players. In a very real sense, the choice and constitution through modifications of the game avatar was a strategic form of persona production, and can be played out in multiple forms, as players switch between characters and their avatars. Likewise, the "real" expression of the player as a gamer in a gaming community was also a form of strategic identity that could potentially separate new players or "noobs" from more experienced players. 
One of these role-playing games developed in the 1990s and still played today is intriguingly called Persona, and represents another prevalent way in which persona is thought of in the contemporary moment, and specifically in online gameplay. Persona the game launched in 1996 for Playstation by the Japanese company Atlus, and connected indirectly to the Shin Megami Tensai series (Wartlick). Over time, the actual title of Persona-and there have now been 8 versions of the game-simplified in its acknowledgement of the centrality of its key trope and difference from other role-playing games that emerged in the post-MUD ${ }^{3}$ era of roleplaying games. As opposed to being set in some medieval-inspired universe, Persona was contemporary and set in a high school. The title refers to how players can release or call forth versions of themselves-personas-to perform certain more powerful tasks that are beyond their human-world. In various newer versions of the Persona game, it becomes clear that these released or latent versions of player/characters as personas emerge from some underside of the unconscious. Various tropes in the game are movements into liminal spaces from day into night, and the personas are ways in which the character discovers more about themselves-their hidden selves.

In many ways, Persona has a loose, mysterious, ethereal, and alluring connection to the psychological dimensions of how persona is perceived in contemporary culture. Similar to Jung, the personal demons or personas in the game emerge out of the shadows to inhabit temporarily some space between the real and the world of shadows. Without over-theorizing the constitution of the particular game, it does point to an exacting position or zone of persona that is between the social world and the individual. Game culture consciously moves the individual into a zone of production and constitution of public identity and, like other games, certain extensions of the self-"specific characters"-provide distinctive repertoires to assist the player in negotiating a particular world. Persona in these versions of online culture is both strategic and tactical as well as relies on a kind of "persona literacy" (Marshall, "Monitoring Persona" 125). Playing online games builds the capacity of the individual player to understand the various and differentiated forms of online personas and cultivates this understanding of the public self in action.

Although it may seem quite a different direction to focus on industry in the final section of our historical roadmap of the uses of persona, it nonetheless represents one of the other major ways in which the concept of persona has been applied, and predates the research trajectories that have informed this journal. In 1999, Alan Cooper wrote a highly influential book in the area of technological design entitled The Inmates are Running the Asylum, where he detailed techniques to involve the end-users in the process of design and production. For Cooper (and a host of others that have followed him), persona identifies a way to creatively construct the type of person that is most likely to use the application. Because software development implies a form of interaction in it structural development, this conceptualization of an end-product user of a particular technological program has to be imagined to ensure that a technology's application makes sense. If the production of a technology product is a series of "coders" who think like coders, a technology and software company needs to imagine the intersection of their code-construction with a consumer. Personas then are the consumers of the products configured into types and probabilities of likely uses of a technology product. Lene Nielsen has extended this approach by ensuring researchers and designers conduct adequate research before the probable personas are integrated into product design. Her ten-step process of first identifying personas in terms of a range of likely and targeted users and profiles, and then using personas regularly to test the product as it is being developed and fine-tuned, perhaps represents the most sophisticated and adaptable use of persona in technological design work (Nielsen, 3,10-11). It is worth noting that one of the goals in integrating personas into the 
design process is to limit the numbers of personas who are actually developed and "interacting" with the different steps: too many personas confuses the design process.

What is interesting about Nielsen's approach, and the parallel "lifecycle" technique that corporate consultants John Pruitt and Tamara Adlin have developed, is that they are heavily involved in the production of possible stories-scenarios-that allow for a kind of projection of whether a design will work with particular end-users or consumers. Personas are fictive, but nonetheless most often built from data about likely users; personas perform forms of interaction and thereby help fine-tune the design and development of a product. How we can define this industrial and technologically-inspired use of persona is that it is a technique of simplification of the collective into the individual. Employing the term persona similarly models for companies the capacity to move between individual practice and social patterns, and then recalibrate that back into individualized fabrications for the eventual use of a form of software or a new "app." So, instead of the industrial model being antithetical to some of the other meanings and directions of persona, it is precisely strategic, openly fictive, and clearly a negotiation of the relationship between the individual and the social in order to construct a projection of a self. The contested public dimension of persona that we have foregrounded throughout our historical review is, therefore, the only element that is overlooked in this attempt by industrially-inspired researchers.

\section{PARALLEL WORLDS}

From this historical and etymological reading of the deployment of persona in many contexts, it is important to understand that there have been parallel research directions in related disciplines that are also valuable in understanding persona and, more importantly, are seeing its relevance in the contemporary moment. These parallel worlds have, in actuality, been very influential in the intellectual location of this journal. Our efforts here to establish the intellectual space and justification for Persona Studies therefore need to address the connected and generally supportive relations; but it should be also understood that this essay can only provide a vignette-like series of connections. These issues around connections will no doubt be explored in much greater detail in this issue and the succeeding issues and years of the journal's existence.

First, somewhere near the core of Persona Studies is a recognition of the complexity of agency. Agency has never been easily defined, but some of the best efforts at understanding it have emerged from Cultural Studies. This value of Cultural Studies is instrumental in positioning the work and the future work of Persona Studies. It is useful to recall John Fiske's phrase most eloquently developed in Understanding Popular Culture (1989), where he refers to the "art of making do" (Fiske, 28) as a defining motif and directly referenced in a recent work on methods in Persona Studies (Marshall, Moore and Barbour). This phrase embodies a great deal in Cultural Studies. It takes on de Certeau's notion of the strategic and the tactical as a way we (collectively) negotiate our way through the world: we use the available resources and make it work for ourselves and in order for these practices to become meaningful in our lives. Persona Studies is pursuing this investigation of the art and the making of negotiated identities. Where much of Cultural Studies has focused on collective configurations of meaning-for example, subculture-Persona Studies looks at how the individual moves into the social spaces and presents the self. As we have identified, Persona Studies is turning the approach of cultural studies on its head-not in some negation, but rather in a refocussing of critical examination of how the individual gains or articulates agency. The current reconfiguration and privileging of the individual as the gatekeeper in online culture has made this focus on agency of increasing 
importance. The complexity of reconfigured structures of power in this differently constituted era of personalization demands this refocus on the individual and its configuration of the social through persona.

Second, another area or subfield that has been critical in the emergence of Persona Studies is Celebrity Studies. The investigation of celebrity has operated as a remarkable precursor for understanding persona. The study of celebrity itself has emerged from related fields of media studies, leadership in political and business studies, performance studies, popular culture, and film studies, as each of these areas has explored in-depth the play of the highly visible individual in different environments. Each of these areas has also intersected with biographical and autobiographical studies, and the related areas of life writing in their exploration of the presentation of the public figure in all sorts of environments. What is critical to understanding celebrity is to recognise that it is an investigation of the textual and the extratextual elements of a particular public personality. Augmenting this research is the close study of the audience and fans that celebrities produce with incredible regularity.

How we read celebrity from the position of Persona Studies is that celebrity represents a powerfully visible exemplification of persona: celebrities are public presentations of the self and they inhabit the active negotiation of the individual defined and reconfigured as social phenomenon. Moreover, they operate in a pedagogical way as individuals use the way that celebrities present themselves to pattern their own forms of the mediatization of the self (see Marshall "Promotion"; Marshall "Celebrity"). Celebrity, from a Persona Studies perspective, is therefore a subset of the wider play of persona. Particularly with the massive appropriation and integration of online culture and social media, the construction of a public persona has become pandemic and the mediatization of the self has become enacted in parallel social networks.

Persona Studies is also very much linked with the various approaches to the study of online culture. For some, this is grouped in Internet Studies; for others, it is better defined as digital sociology; and for still others, in terms of the online reconstruction of interpersonal and mediated communication. Whatever way that online culture is identified, what Persona Studies underlines is that there is a clear process of personalization and mediatization of the personal that both organizes and monetizes the current generation of the Web. Indeed, the push to monitor and share the self in some mediated way, defines a great deal of the contemporary cultural experience as billions engage in forms of social media across the globe. Alice Marwick's innovative study of the online selves of the tech community of Silicon Valley reveals the leading edge and strategic dimensions of this construction of an edited or life-streaming public identity: value and reputation, she reveals, are at play in this social media/mediated world. Self-branding becomes both acceptable and naturalized in what Alison Hearn has effectively explored in her studies of visibility, influence, and the new dimensions of regular online labour. Terri Senft, in her sophisticated and intimate study of web-cam girls, links this new value to previous constructions of individual commodification by calling these personas formations of "microcelebrity" and further explores this through the constraining dimensions of this new public world via the branded self.

Persona-making as a practice, in short, is pandemic. And Persona Studies must necessarily be a discipline that is transdisciplinary, drawing on and cultivating a series of new connections to reveal insights into the contemporary self and the volatile world of the fabricated publics these collective selves conjure. 


\section{THE ISSUE - AND THE ISSUES}

Through its authors and articles, the first issue of Persona Studies begins that intellectual journey that has been explored via these parallel worlds and their parallel journals and conferences up to this point. There have been conferences, articles, and special issues $(M / C$ : Journal of Media and Communication 17:3) that have served as the building ground for the launch of this issue. The interest in those precursors along with the concentrated intellectual engagement of a group of scholars at Deakin University associated with the Persona, Celebrity, Publics Research Group and, specifically, the Persona Node of this group have been the demiurge that have helped build this intellectual work and, ultimately, this intellectual place and space called Persona Studies. This particular issue captures many of those directions from an international group of scholars exploring the dimensions of persona in vital ways. With their work and with our invitation we hope that you engage in this emerging constellation of inquiry.

Three papers in this issue take a single public figure as their subject. Melanie Piper theorises the performance of a comic's persona through the television show Louie, comparing this with the persona of the real-life actor Louis C.K.. Channelling the ideas of front and back stage from Goffman, Piper examines the role of the stand-up comic persona as a complex negotiation between an "authentic" front stage performance, a hidden back stage performance, and a semi-autobiographical television character whose fictional life mirrors and comments on the experiences of the actor who has created him.

SooJin Lee looks at the way that artist Yayoi Kusama has constructed a persona that draws on existing tropes of both Japanese women and visual artists more generally. Lee uses Persona Studies focus to deal with the object focus common within art history, challenging disciplinary tradition by including the artist's persona as a creative medium, and in recognising the persona as holding primacy in Kasuma's body of work.

Andrew Munro's focus is on the persona of Julian Assange, offering a possible new direction for Persona Studies by taking a rhetorical orientation. In providing a close descriptive analysis of the texts created by and about Assange, Munro unpacks the process by which Assange became both famous and infamous, while connecting Assange's persona to the issues of digital leaking, secrecy, and publicity which appear intrinsically connected to this persona.

Taking a broader focus, Meghan Nolan's considers the writerly persona derived from the literary traditions introduced above by examining the process of catfishing online. By using the lens of poetics to consider the performance of this type of online persona, Nolan considers the roles of authority, authenticity, and moral accountability in the making of an authorial persona.

In his paper "The Carer Persona," Timothy Broady usefully and effectively challenges the value and accuracy of Jung's negative approach to persona by exploring the value of a strategically managed identity. The role of the carer often represses aspects that could be seen as more authentic-something antithetical to Jung's idea of persona-in order to assume their supporting and caring role. Indeed, Broady makes the point that this carer persona actually can shift the individual's identity in a positive direction and further challenges the personal and professional identities associated with caring in provocative ways.

Suneel Jethani and Nadine Raydan's paper, "Forming Persona Through Networks," provides a counterpoint within the issue by looking at the role of new technologies-specifically activity trackers-in the construction of persona. By considering wearable sensors as manifestations of systems of control, the authors question the role and effect of trackers in the production and understanding of the self. 
It is with particular pride that our inaugural issue includes not just the traditional scholarly papers introduced above, but also six creative responses to Persona Studies. These art works were exhibited together first in Deakin University's Phoenix Gallery in association with the Persona Studies working papers symposium in February 2015, and challenge us to move beyond the written in our exploration of Persona Studies. Artist and exhibition curator, Glenn D'Cruz, provides an introduction to these works, drawn from the exhibition program. We hope to continue to incorporate creative works into Persona Studies and look forward to continuing a collective exploration of persona with our diverse international community of scholars.

\section{END NOTES}

${ }^{1}$ Prosopon has also since been used to describe the historical research tradition called "prosopography," as well as a particular form of theological investigation into the person.

${ }^{2}$ From its roots, the plural of persona can either be personae or personas. The journal and this article have chosen to identify one that both sounds plural when spoken and looks plural when in text form.

${ }^{3}$ MUDs originally referred to the first generation of online role-playing games and were generally set in fantasy worlds and filled with monsters and other imaginary beings. MUDs is an acronym that stood for Multi-User Dungeons which identified that these first generation of online games were linked to the board and role-playing game Dungeons and Dragons. Subsequently, MUD stood for Multi-User Domains or Dimensions.

\section{WORKS CITED}

Allard, Julie "Le Personnage En Politique: Secret Et Apparence Chez Hannah Arendt." Personne/Personnage. Eds. Lenain, Thierry and Aline Wiame. Paris: Librairie Philosophique J. Vrin, 2011. 25-43. Print.

Arendt, Hannah. "The Public and the Private Realm." The Portable Hannah Arendt. Ed. Peter Baehr. New York: Penguin, 2000. 182-230. Print.

Butler, Judith. Gender Trouble. New York: Routledge, 1990. Print.

---. "Performative Agency." Journal of Cultural Economy 3.2 (2010): 147-61. Print.

Cairns, Michael. "Five predictions for Academic Publishing in 2015." Content Forward. Publishing Technology, 14 Jan. 2015. Web. 16 Apr. 2015.

Cooper, Alan. The Inmates Are Running the Asylum : Why High-Tech Products Drive Us Crazy and How to Restore the Sanity. Indianapolis: Prentice Hall, 1999. Print.

Fawkes, Johanna, "Cultural Complexes in Professional Ethics." Journal of Jungian Scholarly Studies 6.8 (2010): 1-13. Web.

Fiske, John. Understanding Popular Culture. Boston: Unwin Hyman, 1989. Print.

Fowler, H. W., and R. W. Burchfield. Fowler's Modern English Usage. 3rd ed. Oxford: Oxford UP, 2004. Print.

Giddens, Anthony. Modernity and Self-Identity : Self and Society in the Late Modern Age. Cambridge: Polity, 1991. Print.

Goffman, Erving. The Presentation of Self in Everday Life. USA: Anchor Books, 1959. Print.

Hearn, A. "Structuring Feeling: Web 2.0, Online Ranking and the Digital Reputation Economy." Ephemera: Theory and politics in organization 10.3/4 (2010): 421-38. Print. 
Hearn, A., and S. Schoenhoff. "From Celebrity to Influencer: Tracing the Diffusion of Celebrity Value across the Data Stream." Companion to Celebrity Studies. Eds. Marshall, P. David and Sean Redmond. Boston: Wiley, 2015. Print.

Hilliard, Kyle. "What is Shin Megami Tensei: Persona? Gameinformer 4 Aug. 2012. Web. 15 Apr. 2015.

Hollien, H. On Vocal Registers, University of Florida, Communication Sciences Laboratory, 1972. Web. 27 Nov. 2013.

Jung, C. G., et al. Two Essays on Analytical Psychology. 2nd ed. Princeton, N.J.: Princeton UP, 1966. Print

Jung, C. G. Psychological Types. The Collected Works of C.G. Jung. Vol. 6. London: Routledge, 1991. Print.

Landy, Robert J. Persona and Performance: The Meaning of Role in Drama, Therapy, and Everyday Life. New York: Guilford Press, 1993. Print.

Marshall, P. D. "The Promotion and Presentation of the Self: Celebrity as Marker of Presentational Media." Celebrity Studies 1.1 (2010): 35-48. Print.

Marshall, P. David. Celebrity and Power: Fame in Contemporary Culture - 2nd Edition. Minneapolis: Uof Minnesota P, 2014. Print.

---. "Monitoring Persona: Mediatized Identity, Lifestreaming and the Edited Public Self." Frame: Journal of Literary Studies 28.1 (2015): 113-131. Print.

Marshall, P. David, Chris Moore and Kim Barbour. "Persona as Method: exploring celebrity and the public self through persona studies" Celebrity Studies 6.2 (2015). Forthcoming.

Marwick, Alice E. Status Update : Celebrity, Publicity, and Branding in the Social Media Age. New Haven and London: Yale UP, 2013. Print.

Nielsen, Lene. Personas - User Focused Design. London: Springer, 2013. EBook.

Phillips, Angus and Bill Cope. The Future of the Academic Journal. Oxford: Elsevier Science, 2014. EBook.

Pruitt, John, and Tamara Adlin. The Persona Lifecycle : Keeping People in Mind Throughout Product Design. Boston: Elsevier, 2006. Print.

Reiss, Timothy J. Mirages of the Selfe : Patterns of Personhood in Ancient and Early Modern Europe. Stanford, Calif.: Stanford University Press, 2003. Print.

Senft, Theresa M. Camgirls : Celebrity \& Community in the Age of Social Networks. Digital Formations. New York: Peter Lang, 2008. Print.

---. "Microcelebrity and the Branded Self." A Companion to New Media Dynamics. Eds. Axel Bruns, Jean Burgess and John Hartley. Chichester: John Wiley \& Sons, 2013. 346-54. Print.

Turkle, Sherry. Life on the Screen : Identity in the Age of the Internet. New York: Simon \& Schuster, 1995. Print.

Wallace, David Foster. Infinite Jest: A Novel. Boston: Little, Brown and Company, 1996. Print.

P. David Marshall holds a research professorship and personal chair in New Media, Communication and Cultural Studies at Deakin University. He is the author, co-author, editor, or co-editor of many books including Celebrity and Power, $2^{\text {nd }}$ Edition (2014), Companion to Celebrity (November, 2015), New Media Cultures (2004), Celebrity Culture Reader (2006), and Fame Games 2000. His current research is primarily focused on persona as way to understand the presentation of the contemporary and online public self.

Kim Barbour recently completed her doctorate in communication, online culture, and persona studies with an investigation of the online presentations of fringe artists. She has published and presented on academic persona, digital identity, and the presentation of the self in a variety of leading publications and at international conferences. She is currently based at Deakin University where she is a research fellow associated with the Persona, Celebrity, Publics Research Group and teaches in the School of Communication and Creative Arts. 